\title{
A Sea Trial of Air-Lift Concept Artificial Upwelling in the East China Sea
}

\author{
YIWEN PAN AND YIFAN LI \\ Department of Ocean Science, Zhejiang University, Zhoushan, China \\ WEI FAN, DAHAi ZHANG, AND YONGFA QIANG \\ Department of Ocean Engineering, Zhejiang University, Zhoushan, China \\ ZONG-PEI JIANG \\ Department of Ocean Science, Zhejiang University, Zhoushan, China \\ YING CHEN \\ Department of Ocean Engineering, Zhejiang University, Zhoushan, China
}

(Manuscript received 21 December 2018, in final form 2 August 2019)

\begin{abstract}
Artificial upwelling (AU), as one of the geoengineering tools, has received worldwide attention because of its potential ability to actualize ocean fertilization in a sustainable way. The severe challenges of AU are the design and fabrication of a technologically robust device with structural longevity that can maintain the function in the variable and complex hydrodynamics of the upper ocean. In this work, a sea trial of an air-lift concept AU system driven by self-powered energy was carried out in the East China Sea (ECS; $30^{\circ} 8^{\prime} 14^{\prime \prime} \mathrm{N}$, $122^{\circ} 44^{\prime} 59^{\prime \prime} \mathrm{E}$ ) to assess the logistics of at-sea deployment and the durability of the equipment under extremely complex hydrodynamic conditions from 3 to 7 September 2014. Seawater below the thermocline layer was measured to be uplifted from approximately $30 \mathrm{~m}$ to the euphotic layer with a volumetric upwelling rate of $155.43 \mathrm{~m}^{3} \mathrm{~h}^{-1}$ and total inputs of $2.8 \mathrm{~mol} \mathrm{~h}^{-1} \mathrm{NO}_{3}^{-}, 0.15 \mathrm{~mol} \mathrm{~h}^{-1} \mathrm{PO}_{4}^{3-}$, and $4.41 \mathrm{~mol} \mathrm{~h}^{-1} \mathrm{SiO}_{4}^{3-}$. A plume formed by cold, saline deep ocean water (DOW) was tracked by a drifting buoy system with a mixing ratio of $37 \%-51 \%$ DOW at the depth of $18-22 \mathrm{~m}$, which conforms to the simulation results. During the AU's application, disturbance in the vertical hydrological structure could be observed. However, diatom (Skeletonema costatum) blooming from somewhere in the outer ECS floated to the sea trial region on the second day after the AU's application, which makes it hard to strip off the biochemical effects of AU from the effects of $S$. costatum bloom.
\end{abstract}

\section{Introduction}

The ocean is regarded as a possible reservoir as its role of a major sink of anthropogenic $\mathrm{CO}_{2}$ since the industrial revolution. In most oceans, primary production is limited by the availability of the macronutrients (e.g., $\mathrm{N}, \mathrm{P}$, or Si) or essential micronutrients (e.g., Fe) (Arrigo et al. 1999; Dutkiewicz et al. 2005). If large-scale ocean fertilization could be achieved in a sustainable way, the rate of photosynthesis will be stimulated, which could probably alleviate the great pressures and concerns on the problems of ocean fish stocks and human-driven

Corresponding author: Wei Fan, wayfan@zju.edu.cn climate change (Lovelock and Rapley 2007; Kirke 2003). Artificial upwelling (AU) could bring cold, nutrient-rich, deep ocean water (DOW) to the euphotic zone, which could supplement and adjust the essential macro- and micronutrients concentrations. AU is considered as one of the geoengineering techniques that could potentially increase the marine fish productivity and probably accelerate the transfer of $\mathrm{CO}_{2}$ to the ocean by enhancing the export of organic carbon to the deep ocean by stimulating the rate of photosynthesis of phytoplankton (Ye et al. 2013; Hung and Gong 2011; Tsuchiya et al. 2017). Simulation models have shown that the highest concentration in the DOW-formed plume could be achieved when optical technical settings 
of the AU was set according to the regional surface current speed and the vertical density distribution (Fan et al. 2015; Pan et al. 2015, 2018). The enhancement of primary production could be possibly up to 3 times by use of AU (Mizumukai et al. 2008; Handå et al. 2013).

The current knowledge on the development of AU systems and their potential environmental effects was reviewed in Pan et al. (2016). Briefly, the research on AU over the past few decades has generated a range of devices of different types. Some of them have been successfully applied in the field with enhancement of primary production (Masuda et al. 2010; Aure et al. 2007; Maruyama et al. 2011; McClimans et al. 2002). However, the increase in chlorophyll a ( $\mathrm{Chl} \mathrm{a)} \mathrm{concen-}$ tration and nutrients were only observed in types of AU sea trials with an electric power supply except for the "perpetual salt fountain concept" AU system. Maruyama et al. (2011) proposed a target of 3 times above the $\mathrm{Chl}$ a concentration around the outlet pipe in the sea trial using the perpetual salt fountain concept AU. However, the amount of uplifted DOW seemed to be too small to sustain the minimum nutrient concentration requirements of an ocean farming project (Zhang et al. 2004; Williamson et al. 2009). To impact the open ocean, or even a small patch of it, more than one pipe must be functioning for at least several weeks. Self-power is thus crucial to assure the feasibility and sustainability for practical application of the AU, especially in the open sea. White et al. (2010) conducted a wave-pumppowered AU sea trial to the north of Oahu, Hawaii. The pump materials halted the experiment, although DOW was rapidly transported to the surface ocean by $300-\mathrm{m}$ pipes at first. The severe challenges of AU are the design and fabrication of a technologically robust device with structural longevity and self-supplying energy that can maintain the function in the variable and complex hydrodynamics of the upper ocean. Research on AU systems mainly focuses on increasing the uplifting efficiency and using renewable energy.

Liang and Peng (2005) proposed an air-lift pump for upwelling DOW with high efficiency, which could simply be powered by injecting compressed gas through the lower part of a pipe. A schematic diagram of the experimental setup of this concept pump is depicted in Fig. 1. It consists of a vertical pipe for water suction and a gas injection section pipe that transports the compressed air generated from solar power into the lower part of the vertical pipe. The injected gas bubbles suspend in the water and make the average density of the two-phase mixture in the pipe less than the surrounding fluid, which thus pump the seawater up in the same direction as the air. The device is self-powered by a distributed generation system composed of a photovoltaic

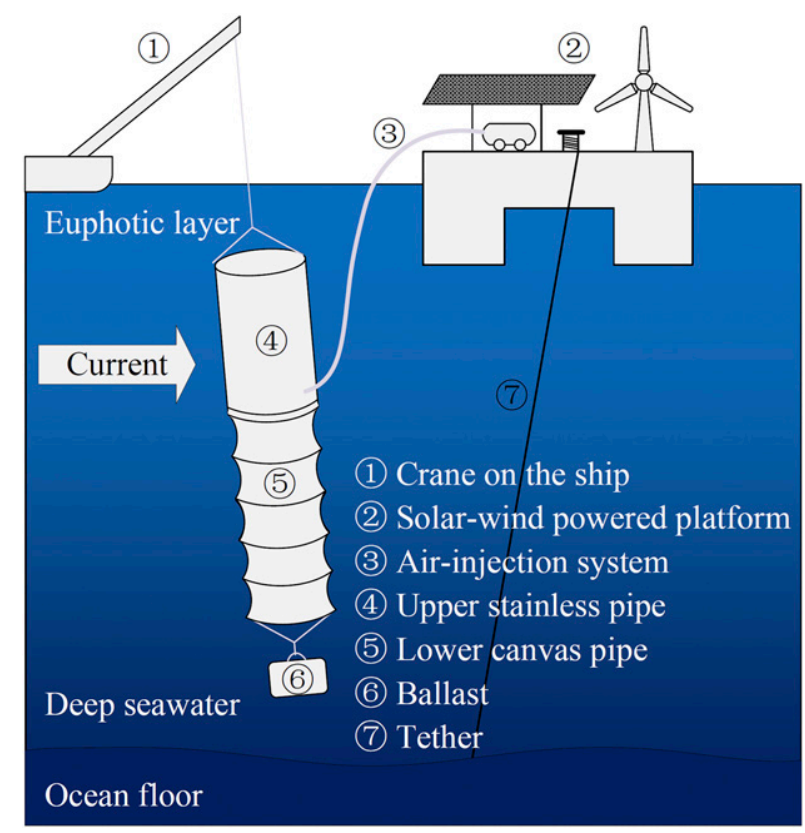

FIG. 1. Schematic diagram of the experimental setup of air-lift concept $\mathrm{AU}$ in the sea trial.

array, wind turbines, and a wave energy converter array (Zhang et al. 2013; Zhang et al. 2016). After two field experiments conducted in Qiandao Lake (lake trials), it was proved that deep water could be uplifted to the upper layer using the air-lift concept AU with a water flow rate versus airflow rate around 40 (Fan et al. 2013). To assess the logistics of at-sea deployment and the durability of the equipment under open-ocean conditions, the air-lift concept AU driven by self-powered energy was tested in the sea near Dongfushan Island in the East China Sea (ECS; $30^{\circ} 8^{\prime} 14^{\prime \prime} \mathrm{N}, 122^{\circ} 44^{\prime} 59^{\prime \prime} \mathrm{E}$ ) (see Fig. 2). Dongfushan Island is located in the eastern open water of the Zhoushan Archipelago, which are at the junction of the southeast waters offshore the Changjiang River and the outer edge of the Hangzhou Bay. The hydrodynamic conditions there are extremely complex, with the combined influences from the Changjiang River and the tidalinduced water exchange between the Hangzhou Bay and the ECS (Zhang et al. 2018; Fang et al. 2004). The main aim of the sea trial is to examine the structural robustness of the devices in the complex hydrodynamics of the ocean and evaluate its potential environmental impacts.

\section{Methods}

\section{a. Experimental setup and deployment}

The AU system mainly consists of an upwelling pipe, an air compressor, air supply pipes, and hybrid energy 


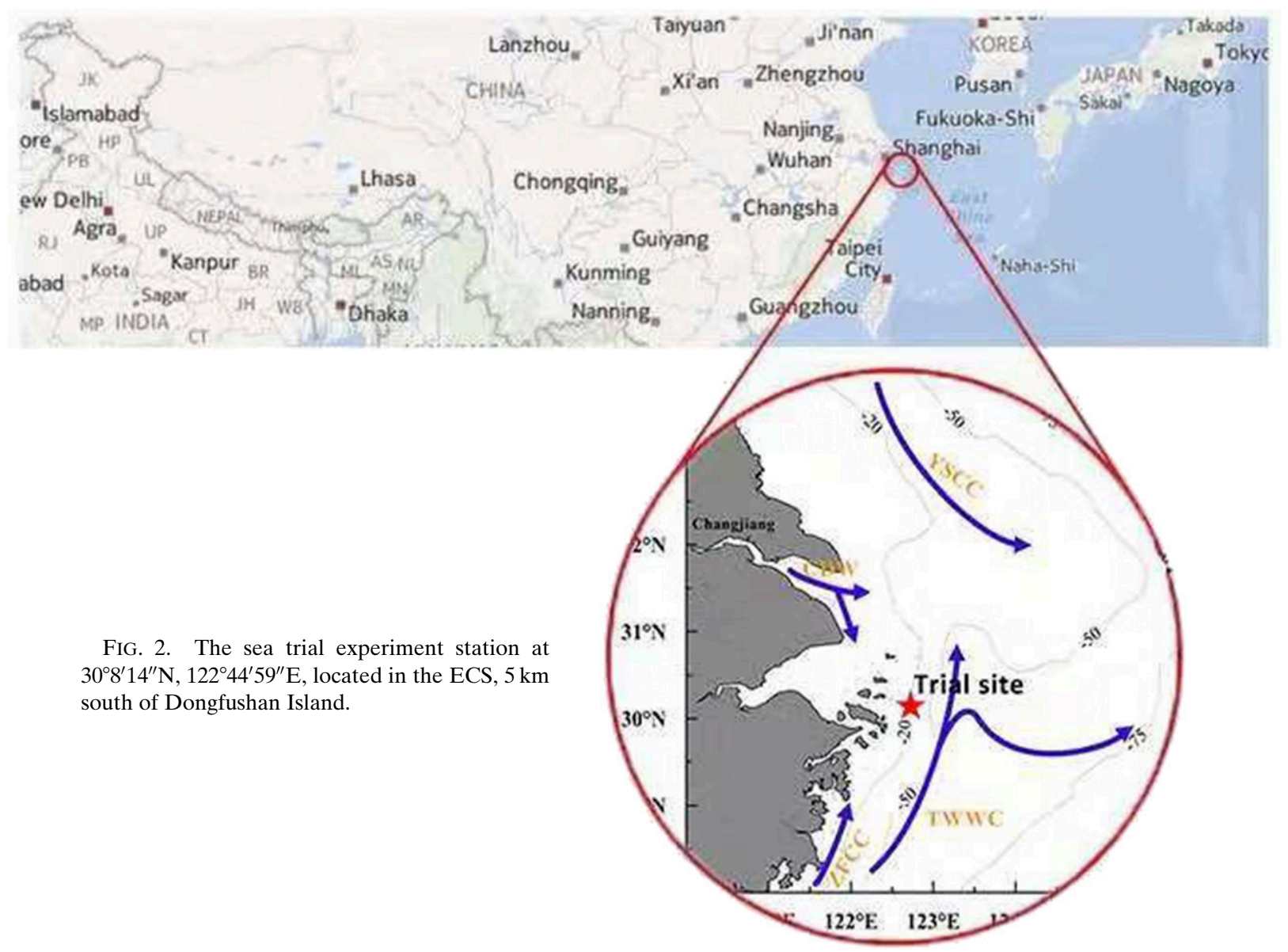

platform. The schematic of the sea trial setup is depicted in Fig. 1. The upwelling pipe is $20 \mathrm{~m}$ long with a $1-\mathrm{m}$ internal diameter, composed of two sections made of different materials. The upper section is $6 \mathrm{~m}$, made of stainless steel. The bottom section is $14 \mathrm{~m}$, made of canvas with two crossed stainless steel as supports. At the end of stainless pipe, around $4 \mathrm{~m}$ below the upper end of the pipe, the air injection nozzle made of stainless steel is placed at the center of the upwelling pipe. Compressed air produced by an air compressor, modulated by a pressure control valve, and measured by a mass flowmeter, is delivered at the end of stainless pipe through an external pipe. In this way, the bubbles could free themselves more easily and not cling to the pipe wall. The mass flowmeter is used to control the constant airflow rates, while the pressure control valve is used to moderately reduce the air pressure. The compressed air is metered and the volume flow rate is determined by an electromagnetic airflow meter connected to the air supply pipe. The air compressor (model: JBao 3540) is driven by a distributed generation (DG) system. Detailed description of the DG system was introduced in Zhang et al. (2016). Roughly, the DG system for air-lift AU consists of DG units of a wind turbine, a wave energy converter (WEC) array, a PV array, a diesel generator, and an air compressor. The hybrid energy and air injection system are accommodated in a $5 \mathrm{~m} \times 2.5 \mathrm{~m}$ floating platform (Fig. 3).

To conveniently deploy the floating platform and artificial pipe, an engineering ship with a 30-m-long crane was used in the trial. The crane should be kept at a suitable speed to exclude air inside the pipe over time, in order to prevent pipe deformation resulting from the external squeeze by water. A ballast of $250 \mathrm{~kg}$ is suspended on the lower end of the pipe to keep it erect. It must be pointed out that the ballast is supported by steel cables outside the upwelling pipe instead of the pipe itself so that the canvas has enough stress to deal with the shear force caused by waves and tides in the sea. The floating platform is drifted away with some strings attached. The upwelling pipe is hooked and fixed by the crane, while the buoy fluctuates with the waves. There is only a flexible compressed air pipe between the upwelling pipe 


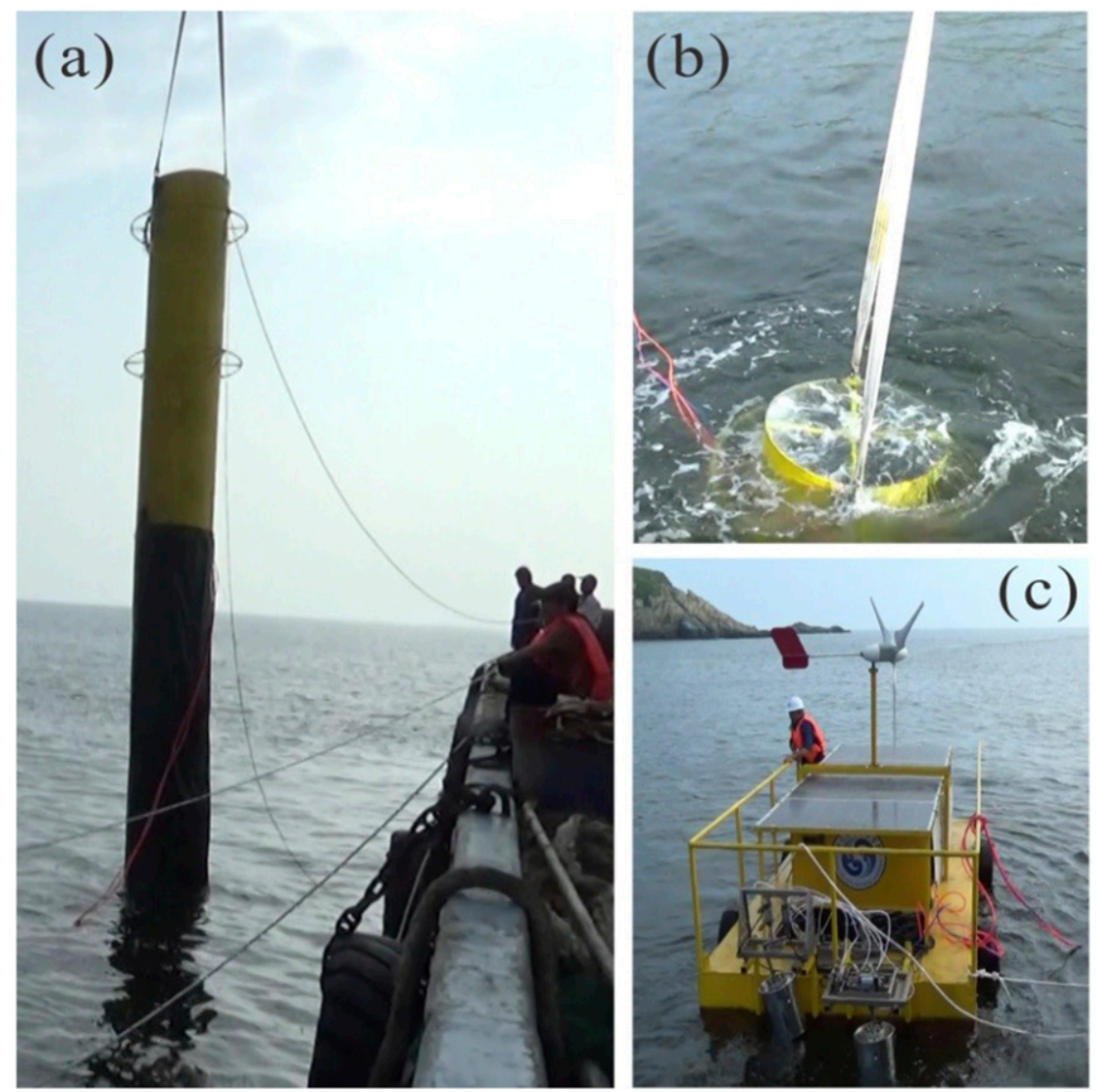

FIG. 3. Photos of AU's application in the sea trial: (a) deploying the upwelling pipe on the deck,

(b) installation of the upwelling pipe, and (c) the floating platform for the energy supply.

and the buoy, so they move independently of each other (Fig. 1).

\section{b. Field observations}

Vertical profiles of temperature $T$, salinity $S$, dissolved oxygen concentration (DO), $\mathrm{Chl} \mathrm{a}, \mathrm{pH}$, and turbidity were recorded in situ with a precalibrated multiparameter water analyzer [Yellow Spring Instruments (YSI); Yellow Springs, Ohio], with precisions of $\pm 0.01^{\circ} \mathrm{C}$ and \pm 0.01 salinity units. Seawater samples were taken with Niskin bottles at depths of $0,5,15$, and $25 \mathrm{~m}(35 \mathrm{~m})$. Samples for nutrients $\left(\mathrm{NO}_{3}^{-}+\mathrm{NO}_{2}^{-}, \mathrm{PO}_{4}^{3-}\right.$, and $\left.\mathrm{SiO}_{4}^{3-}\right)$ were achieved after discrete water samples were obtained using 5-L Niskin and Go-Flo bottles. After filtering with a $0.45-\mu \mathrm{m}$ membrane, Samples were stored at $-20^{\circ} \mathrm{C}$ for analysis back in the laboratory.

The upwelling pump was outfitted with a multiparameter water analyzer (YSI) at the top end and a CTD (SBE 16plus V2 SEACAT) at the bottom end. The physicochemical parameters, including $T$ and $S$ of the DOW sucked from the bottom end and discharged from the top pipe could be measured in situ and continuously. An acoustic
Doppler current profiler (ADCP; model: RTDP600) was mounted on the deep bottom to obtain real-time series of currents neighboring the AU system. Mutually orthogonal components of current speeds based on Cartesian coordinates were saved as binary files at 1-min intervals. These raw measurement results can be transformed into current profiles in terms of magnitudes and directions.

A tracer (potassium permanganate solution) release experiment was performed to obtain the volume flow rate of upwelling water. On the ship deck, tracer was prepared in a water tank and subsequently pumped to the bottom end of the upwelling pipe through a flexible pipe with an 8 -mm internal diameter. The one-way valve on the flexible pipe could prevent backflow of the seawater. Three submerged cameras were installed at the outlet of the flexible pipe, which enabled us to obtain the time when the tracer was released from the outlet. The volume flow rate of upwelling water was acquired by recording the time it took for the tracer to rise from the bottom end to the upper end of upwelling pipe. It is important to assess the accuracy of the volume flow rate of upwelling water taking the turbulence and eddies in 


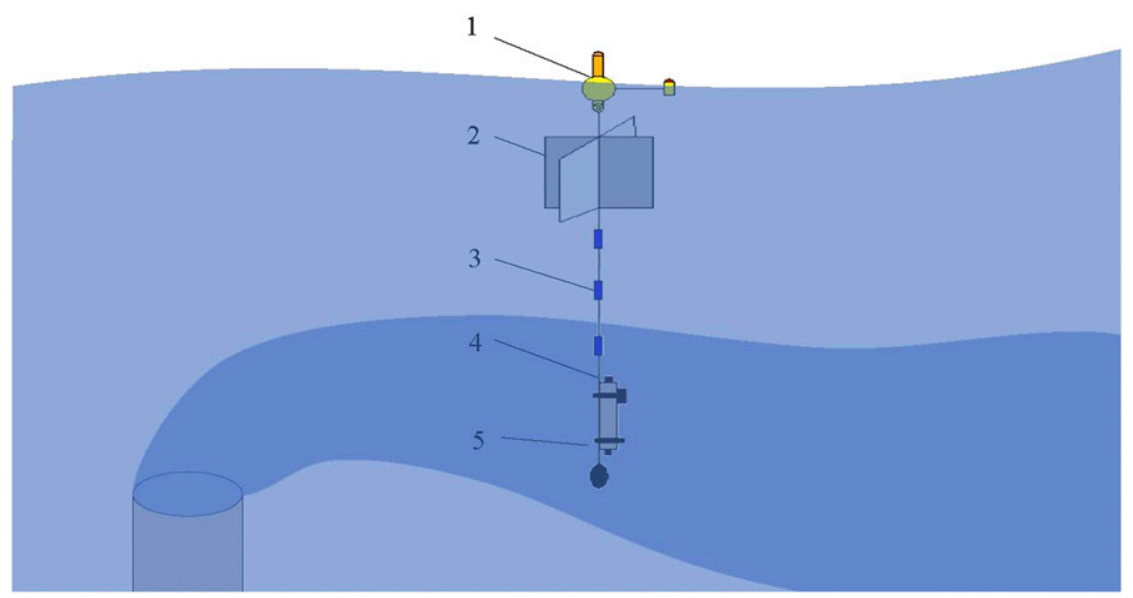

FIG. 4. Components and configuration of drifting buoy system for searching DOW's plume in the sea trial: 1 is the drifting buoy with GPS recorder, 2 is the cross-sail drogue, 3 is the temperature sensors, 4 is the multiple-parameter YSI sensor system, and 5 is the counterweight ballast.

the pipe into account. In our previous lake-trial research (Fan et al. 2013), an electromagnetic flowmeter, model MGG/KLL-magB, was installed in the vertical upward pipe at the bottom of the gas-injection section. Two methods (by using the electromagnetic flowmeter and the tracer) were implemented to measure the volume flow rate of upwelling water at the same time. The results showed that the flow-rate measurement using the tracer was found to have an accuracy (compared with the electromagnetic flowmeter) of better than $12.4 \%$, which was an acceptable value, in the flow-rate range of $100-800 \mathrm{~m}^{3} \mathrm{~h}^{-1}$.

To search the plume trajectory formed by DOW, a drifting buoy system (Fig. 4) was employed during the flood tide period when the directions of the ocean currents at different depths are the same (Fig. 5). The drifting buoy system consists of a white cross board, a drogue attached to the bottom end, a YSI next to the drogue at around $22 \mathrm{~m}$, and three other automatic-logging temperature sensors at 18,14 , and $10 \mathrm{~m}$. The cross sail drogue could help the system drift along the current at the plume layer. The GPS information of the system was recorded by the YSI to trace the drifting trajectory of the buoy. The temperature was recorded at four depths: $10,14,18$, and $22 \mathrm{~m}$. The buoy system was drifted several times to compare the physicochemical parameters between the upwelling area and the nonupwelling area. In some of the searching process, the buoy system is released from the upper end of pipe and the others are far from it.

\section{Results}

\section{a. Study site}

A sea trial was performed in the ECS $\left(30^{\circ} 8^{\prime} 14^{\prime \prime} \mathrm{N}\right.$, $122^{\circ} 44^{\prime} 59^{\prime \prime} \mathrm{E}$ ) from 3 to 7 September 2014 . The sea trial station, located approximately $5 \mathrm{~km}$ south of Dongfushan Island, is an open-sea area east of the Zhoushan Islands, China. The open-sea area is at the southern flank of the Changjiang River estuary and the outer edge of the Hangzhou Bay of China, a wellknown strong-tide region (Fang et al. 2004). There are roughly four dominant water masses in the studied sea area in summer, although the freshwater input from the Changjiang River and the northward inflow of the Taiwan Warm Current (TWWC) are the two main water masses in the estuary (Su 1998; Chen and Wang 1999; Chen 2008; Yang et al. 2012), dominating in the surface and bottom layer, respectively. The Yellow Sea Coastal Current (YSCC) that flows persistently southward and

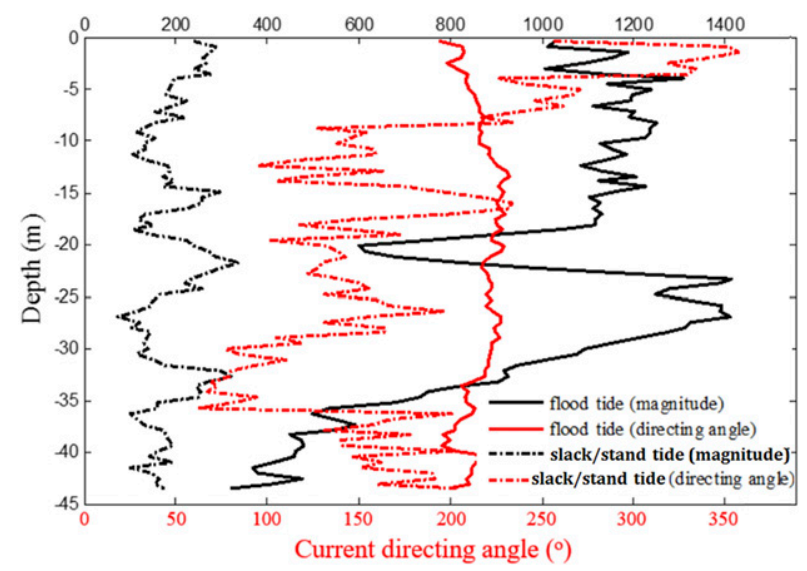

FIG. 5. One current profile at flood tide (solid) and one at slack/stand tide (dash-dotted) in terms of magnitudes and directing angles. The time interval is $6 \mathrm{~h} 10 \mathrm{~min}$ from ADCP data, and the time-averaged velocity and fluctuation are measured by using the ADCP. 

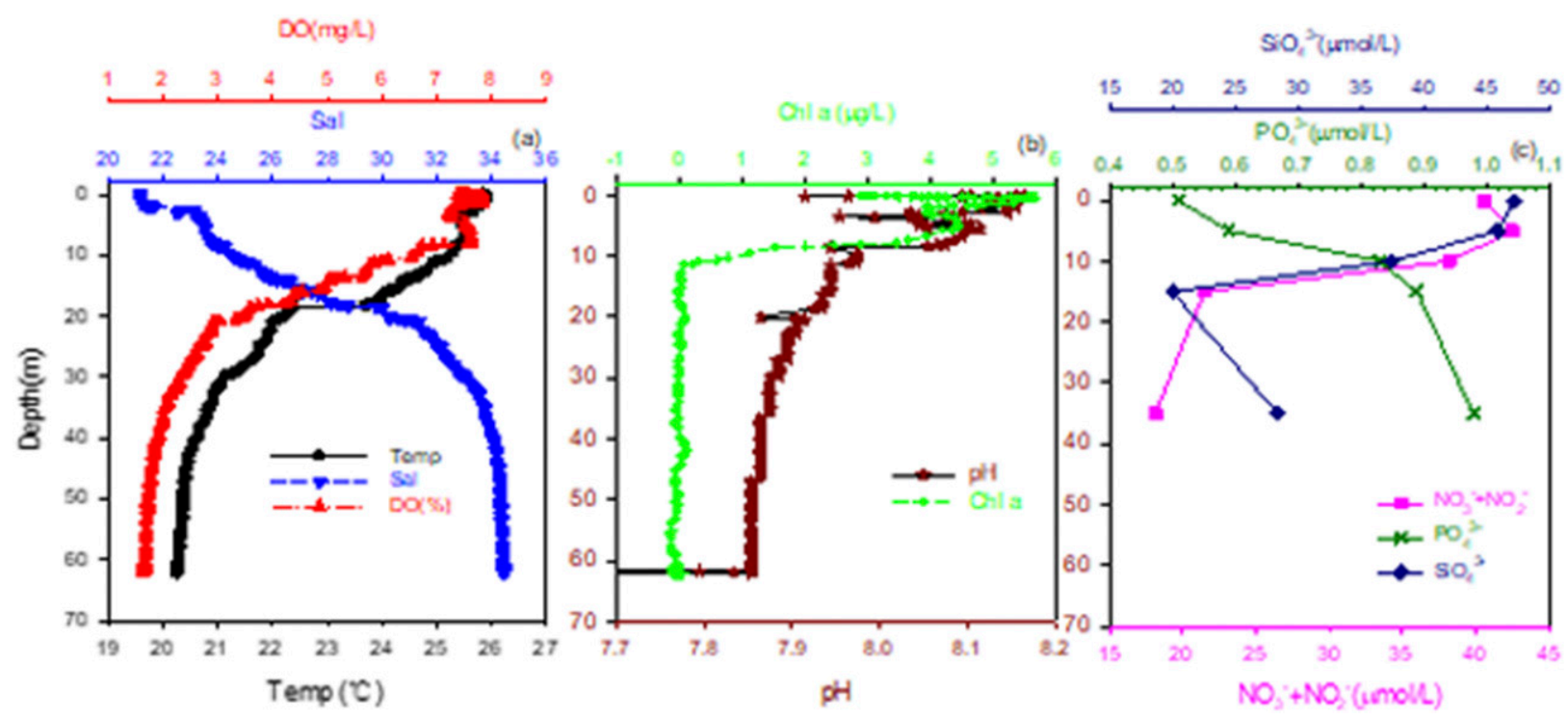

FIG. 6. Typical profile of temperature, salinity, DO, $\mathrm{pH}$, and the concentration of nutrients in the sea trial station before the AU's application.

Zhejiang-Fujian Coastal Current (ZFCC) that flows northward also impact the hydrological conditions in the study site (Chen 2009). Continually supplied Changjiang diluted water (CDW) is of low $S$ and high $T$, while the TWWC derived from Kuroshio subsurface water is the opposite. The interaction between CDW and TWWC at a depth of $20 \mathrm{~m}$ contributes to a thermohaline driven stratification in a broad area.

The current profiles in terms of magnitudes and directing angles are depicted in Fig. 5. The ADCP was located at $43.5 \mathrm{~m}$. Water particles move slowly during slack/stand tide period and obtain much higher speed during flood tide period. The slack/stand tide alternates with the flood tide at a quarter day, showing a semidiurnal tide pattern at the test site. Yet the tidal effect alone cannot explain the discrepancy of current directing angle between two periods. The observation data show that flood tide along the profile propagates in almost the same direction of $180^{\circ}$ for a nominal zero angle marked by the ADCP. On the other hand, a current directing angle of slack/stand tide considerably changes with depth. For water shallower than $5 \mathrm{~m}$, current directing angle of slack/stand tide reaches about $360^{\circ}$, which is exactly opposite to the case of flood tide and can be explained by the motion of CDW. The effect of CDW is apparently attenuated with increasing depths $(>5 \mathrm{~m})$. Then the TWWC is taken into account as a contributor of velocity component perpendicular to the tidal direction, which is about $0.2 \mathrm{~m} \mathrm{~s}^{-1}$ inferred from the profiles of slack/stand tide when the tidal effect could be ignored. The surface current speed reported by Shen et al. (2013) is in the range of $0.2-2.3 \mathrm{~m} \mathrm{~s}^{-1}$, and the average tidal stream is of $5-10 \mathrm{~kW} \mathrm{~m}^{-1}$ in that region, which is a mesotidal estuary. The mean tidal range is $2-3 \mathrm{~m}$ (Fang et al. 2004), which is primarily the result of four main astronomical constituents. Two are semidiurnal and two are diurnal (Zheng et al. 2012; Zhang et al. 2018). By removing the vertical structure of the residual current, which is estimated as a time average of vertical current profiles over one semidiurnal lunar (M2) tidal period, the range of net tidal current speed can be calculated as $0-1.4 \mathrm{~m} \mathrm{~s}^{-1}$. The bottom and density interface also affect the vertical structure of the current speed. The strong density interface is around $20 \mathrm{~m}$ according to the density profile. Near the bottom and around the density interface, boundary friction will cause a decline in the horizontal speed of the current, resulting in a double-peak distribution of the observed current speed.

The typical profiles of $T, S, \mathrm{DO}, \mathrm{Chl}$ a, $\mathrm{pH}$, and the concentration of $\mathrm{P}$ and $\mathrm{N}$ are depicted in Fig. 6, which suggest a strongly stratified profile with a depth of $60 \mathrm{~m}$. The complex hydrodynamic condition make the study site a meaningful sea-trial site and a severe challenge in testing the engineering robustness of an AU system during the whole deploying-duration-recovery period. The sunlight penetration depth at the test site measured by the Secchi disc is approximately $3 \mathrm{~m}$, which suggests the sunlight penetration depth at the test site is about $13-14 \mathrm{~m}$. From the $T$ and $S$ profiles, the thermocline layer begins between $\sim 10$ and $\sim 20 \mathrm{~m}$. The water above $10 \mathrm{~m}$ is warm $\left(\sim 25.5^{\circ} \mathrm{C}\right)$ and less saline $\left(21^{\circ} \mathrm{C}\right.$ for the surface water and $23^{\circ}-24^{\circ} \mathrm{C}$ for the water at $2-9 \mathrm{~m}$ ), which indicates a strong influence of freshwater from CDW. CDW is a major source of nitrate and silicate to 
the coastal ECS (Gong et al. 2006). The nutrient content profile also proves the strong influence of $\mathrm{CDW}$. Higher concentrations of $\mathrm{N}$ and $\mathrm{Si}\left(\sim 40 \mu \mathrm{mol} \mathrm{L}^{-1}\right.$ $\left.\mathrm{NO}_{3}^{-}+\mathrm{NO}_{2}^{-}, \sim 45 \mu \mathrm{mol} \mathrm{L}{ }^{-1} \mathrm{SiO}_{4}^{3-}\right)$ and a lower concentration of $\mathrm{P}\left(\sim 0.5 \mu \mathrm{mol} \mathrm{L}{ }^{-1} \mathrm{PO}_{4}^{3-}\right)$ are in the top layer. Lower concentrations of $\mathrm{N}$ and $\mathrm{Si}\left(\sim 20 \mu \mathrm{mol} \mathrm{L}^{-1}\right.$ $\left.\mathrm{NO}_{3}^{-}+\mathrm{NO}_{2}^{-}, \sim 23 \mu \mathrm{mol} \mathrm{L}^{-1} \mathrm{SiO}_{4}^{3-}\right)$ and a higher concentration of $\mathrm{P}\left(\sim 0.9 \mu \mathrm{mol} \mathrm{L}^{-1} \mathrm{PO}_{4}^{3-}\right)$ are below the thermocline layer. Although atmospheric deposition may also be substantial during Asian dust events and is associated with heavily anthropogenic emissions across East Asia (Zhu et al. 2013; Guo et al. 2014), the intrusion of enhanced TWWC is the most important supplemental source of phosphate (Wang et al. 2018; Chen and Wang 1999). The $\mathrm{Chl} \mathrm{a}, \mathrm{DO}$, and $\mathrm{pH}$ data are associated with each other. The highest values of approximately $5.64 \mu \mathrm{g} \mathrm{L}^{-1}$ (Chl a), $7.85 \mathrm{mg} \mathrm{L}^{-1}$ (DO), and $8.15(\mathrm{pH})$ occur near surface. They decrease a bit and form another maximal value of $4.45 \mu \mathrm{g} \mathrm{L}^{-1}, 7.57 \mathrm{mg} \mathrm{L}^{-1}$, and 8.11 , respectively, around $5 \mathrm{~m}$, indicating that photosynthesis of phytoplankton releases $\mathrm{O}_{2}$ and increases $\mathrm{pH}$ at a water depth above $5 \mathrm{~m}$. The $\mathrm{Chl}$ a, DO, and $\mathrm{pH}$ data quickly decrease with depth after $5 \mathrm{~m}$. The Chl a values decrease to $0 \mu \mathrm{g} \mathrm{L}^{-1}$ after $10 \mathrm{~m}$, the $\mathrm{DO}$ values reduce to less than $2 \mathrm{mg} \mathrm{L}^{-1}$ after $35 \mathrm{~m}$, and the $\mathrm{pH}$ reduces to less than 7.8 , suggesting a hypoxia condition in the bottom.

\section{b. Observed effects of $A U$}

During the AU's application, multiple parameters recorded by CTD at the bottom and YSI at the top could help to tell whether the DOW was delivered to the upper end and from what depth did those DOW originate. The CTD signals (dashed line in Fig. 7a) indicate that the inlet $T$ is approximately $22^{\circ} \mathrm{C}$; when compared to the YSI profiles measured before AU's application (Fig. 7b), it is concluded that the DOW was uplifted from a depth of approximately $30 \mathrm{~m}$.

The monitoring records of YSI in the top pipe in the sea trial are similar to that in the lake trial conducted previously (Fan et al. 2013). The objective of the lake trial is to test the performance of the air-lift pump for $\mathrm{AU}$, and the reader is referred to these for detailed information on the experimental setup and results. Both the records from sea trial and lake trial indicate that the deep depth water of low $T$, low DO, and high $S$ (only in sea trial) was delivered to the top, but there are small differences that should be noticed. The phenomena of air-injecting depths and the related DOW depths between the AU's lake trial and sea trial are different. As illustrated in Fig. 7a, the blue arrows and the black arrows refer to the two scenarios of injecting air at the depths of 8 and $10 \mathrm{~m}$, respectively, in the sea trial.
For either scenario, bubble clusters were observed at the surface water. Yet continuous inspection by YSI showed that only little or no DOW was uplifted and flowed out of the upper end of the pipe in the case of injecting air at $8 \mathrm{~m}$. In the case of injecting air at $10 \mathrm{~m}$, however, cold, salty, hypoxic, and more acerbic DOW was recorded at the upper end of the pipe, suggesting large amount of DOW upwelling instead. The wide variation of $T, S$, and DO data in the upper end of the pipe should be caused by the uplifted mixture of DOW with air bubbles.

The power balance equation of the air-lift artificial upwelling where the minimum energy requirement for an air-lift AU device can be shown as follows Fan et al. (2013), suggesting that the DOW from 48- to 52-m depth could be uplifted to the pipe outlet above the density interface when the air was injected at $8-10-\mathrm{m}$ depth in the upwelling pipe in the sea trial:

$$
E_{i}=E_{o}+E_{k}+E_{\mathrm{ru}},
$$

where $E_{i}$ is the air input power, $E_{o}$ is the power demand of the density difference head, $E_{k}$ is the kinetic energy of the upwelling water, and $E_{\mathrm{ru}}$ is frictional loss power in the upwelling pipe. The sea trial data indicate that when the injection of compressed air is at $8 \mathrm{~m}$, the DOW cannot be uplifted (Fig. 7a). However, in the lake trial, the deep water from at least $30 \mathrm{~m}$ or deeper was uplifted to the upper end according to the $T$ and DO data (Figs. 7c,d), which is consistent with the theoretical calculation (Chen et al. 2013). The differences between the uplifting ability between the lake trial and sea trial could probably be attributed to the inverse intrusion pressure caused by shallow water into the upwelling pipe. During the sea trial, the upper end of the pipe was fixed by the crane, and the pipe inclined forward because of the effect of the ocean current on the lower end of the pipe (Fig. 1). This inclination allows shallow water to flow reversely into the pipe at the upper inlet, which introduces extra resistance to the air-lift upwelling. The experimental data will be invalid once the current is too large and the inclined angle of the upwelling pipe is greater than $12^{\circ}$. An available way to avoid reverse flow of shallow water is to fix the bottom end of the pipe. In that case, ocean current would make the pipe incline backward, which would potentially enhance the upwelling flow rate instead, because the ocean current tends to develop a vortex with a negative pressure gradient near the pipe outlet. The effect of the pipe inclination on upwelling flows deserves further study.

\section{c. Estimated upwelling velocity with injecting air flux}

Upwelling velocity depends on factors such as airflow rate, nozzle shape, and injection-hole diameter. 
(a)
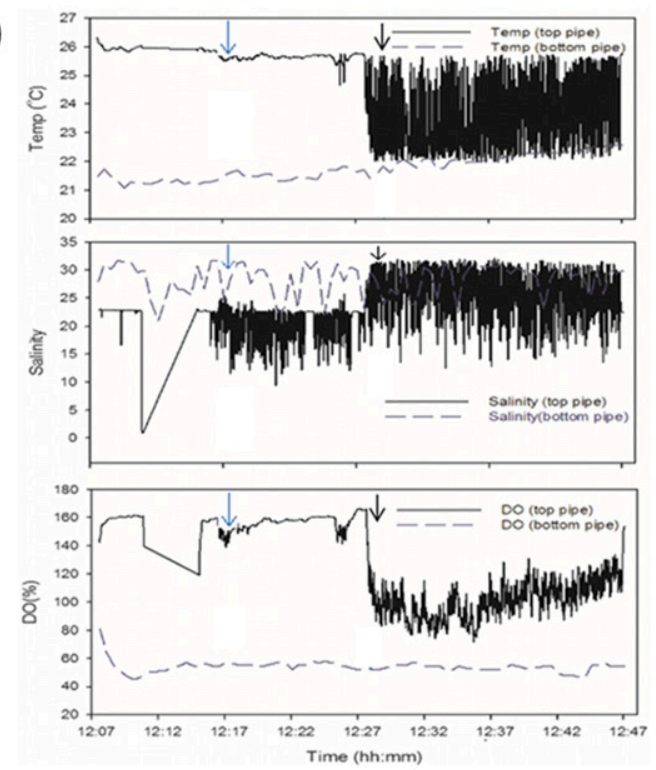

(c) Time series Data of Temperature and DO

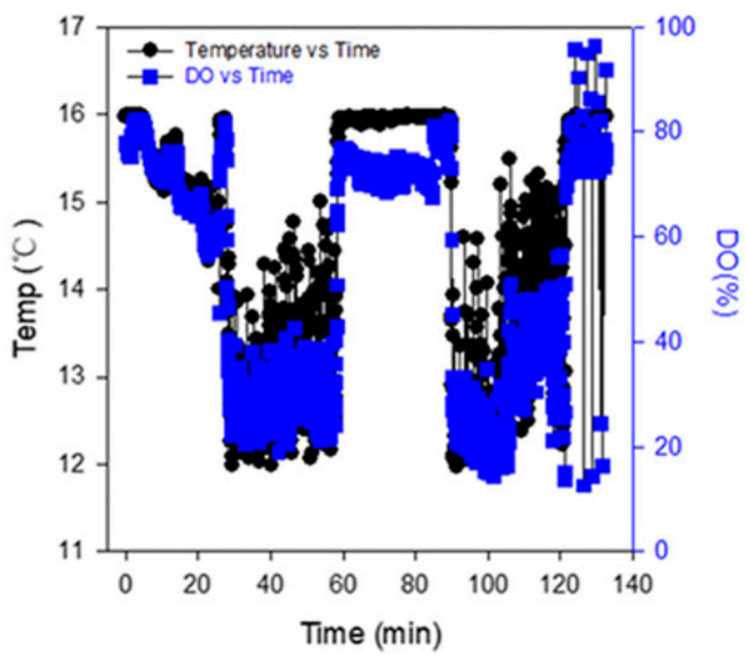

(b)

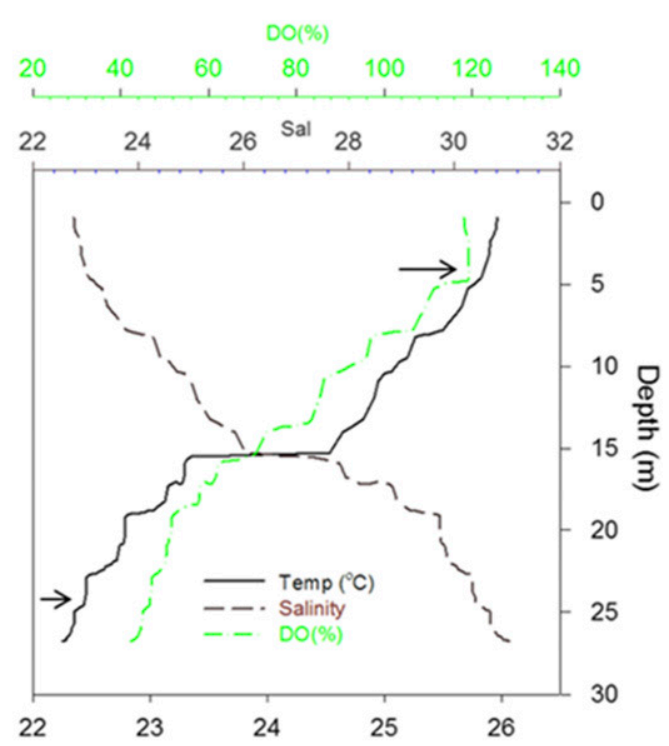

(d) Original profile of Temperature and DO data

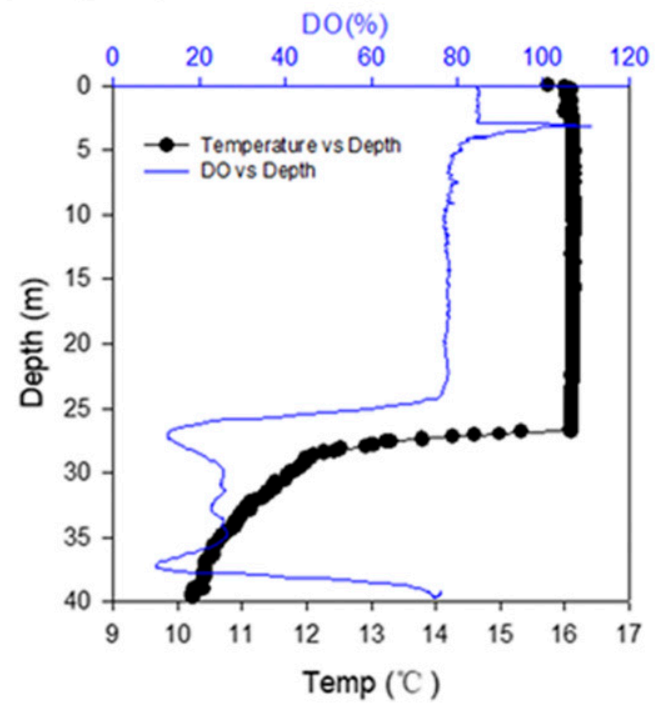

FIG. 7. (left) Time series of data recorded by sensors fixed (a) at the upper and lower ends of the pipe in the sea trial and (c) at the upper end of the pipe in the lake trial. (right) Vertical profiles of $T, S$, and DO in the (b) sea trial and (d) lake trial.

When the injection airflow rate increases, upwelling velocity and flow rate increase accordingly. At an airflow rate of $120 \mathrm{~L} \mathrm{~min}^{-1}$, upwelling velocities are 0.051 and $0.085 \mathrm{~m} \mathrm{~s}^{-1}$ for ring-shaped and star-shaped nozzles, respectively (Fan et al. 2013; Qiang et al. 2018). Besides, injection-hole diameter also plays an important role in influencing upwelling velocity. Figure 8 shows upwelling velocity versus the injection airflow rate for nozzles with hole diameters of $0.5,1$, and $2 \mathrm{~mm}$. Upwelling velocity for a hole diameter of $2 \mathrm{~mm}$ is about 4 times more than that of a hole diameter of $0.5 \mathrm{~mm}$ at an airflow rate of
$120 \mathrm{~L} \mathrm{~min}^{-1}$. The result indicates that increased hole diameter can promote upwelling efficiency. Therefore, a star-shaped nozzle with an injection hole diameter of $2 \mathrm{~mm}$ can achieve an upwelling flow rate of $3300 \mathrm{~L} \mathrm{~min}^{-1}$ when the airflow is $120 \mathrm{~L} \mathrm{~min}^{-1}$.

Comparing with the reported natural upwelling rates $0-1.0 \mathrm{~m} \mathrm{day}^{-1}$ in the eastern tropical South Pacific (Haskell et al. 2015), and 0-2.2 $\mathrm{m} \mathrm{day}^{-1}$ in the equatorial Atlantic (Kadko and Johns 2011), the upwelling rate generated by an air-lift concept pipe could achieve $0.07 \mathrm{~m} \mathrm{~s}^{-1}$, which is much larger than natural upwelling. 


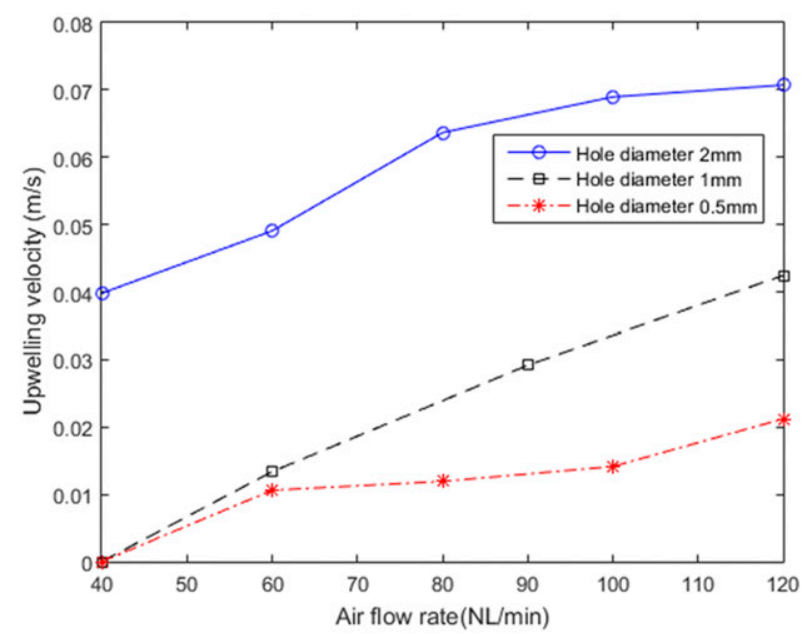

FIG. 8. Variation of upwelling velocity with different hole diameters.

The uplifted water could be $4748 \mathrm{~m}^{3}$ day $^{-1}$ using one upwelling pipe with a nozzle with a $1 \mathrm{~mm}$ hole (continuously pump for $24 \mathrm{~h}$ ). It is rational to deduce that although the scale of a single pipe is extremely small compared to the natural upwelling, the order of magnitude of AU's upwelling rates and the potential of increasing the pipe number made AU an efficient way to reduce the problems caused by stratification that become stronger as a result of global warming.

\section{d. Searching for the DOW's plume}

How to keep the high-density DOW within the euphotic layer and without significant dilution during its spreading has become one of the research interests in AU. If the uplifted DOW was not well mixed, its high density would make it quickly sink out of the euphotic layer (Ouchi et al. 2005). If the DOW is overdiluted, nutrient levels would be reduced out of the minimum limitation to sustain the photosynthesis process of phytoplankton (Williamson et al. 2009). A mathematical model to simulate the discharging DOW's trajectory and concentration distribution has been reported by Fan et al. (2015). It is suggested that in order to make the plume trapped at the density interface, forming the potentially highest concentration of DOW at the far-field, an optimal discharge nozzle height could be calculated according to the regional surface current speed, pumped water flow rate, and pipe diameter.

In the sea trial, one of the goals is to determine the settling depth and the horizontal distribution of the DOW after it flows out of the pipe. Whether the plume could be confirmed by measurement is vital to determining the probability of a biological response. According to the thermocline layer measured on 6 September,

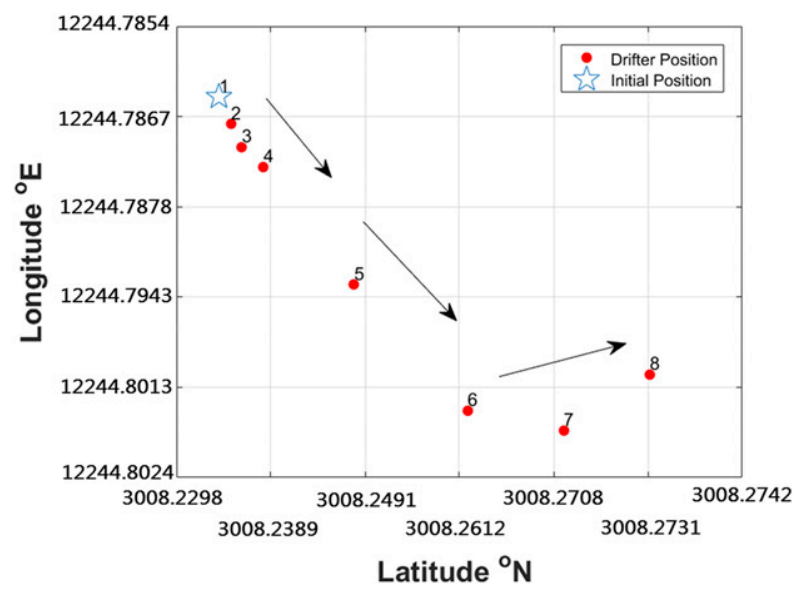

FIG. 9. A buoy-tracking trajectory of the plume-searching experiment.

the pipe was sunk down to uplift 40-m DOW to form an optimal plume. Determining the DOW's plume was carried out by the drifting buoy system. Temperature data from four layers $(10,14,18,22 \mathrm{~m})$ were recorded. DO, salinity, and depth data were recorded at the 22-m layer. Comparisons were made between the drifting buoy system in the upwelling area and in the nonupwelling area. After releasing from the pipe end, the buoy moved along at a velocity of $1.2 \mathrm{~m} \mathrm{~s}^{-1}$ to the southeast, and then shifted generally to the northeast (Fig. 9). The buoy velocity is fast, indicating a high-velocity current at the drogue depth. The YSI's depth sensor in the drifting buoy system exhibit the same $22 \mathrm{~m}$ between the two drifting processes (Figs. 10a,b), the obvious low- $T$ (Fig. 10c), high- $S$, and low-DO signals (Fig. 10e) recorded in the first drifting period in comparison with the second drifting period (Figs. 10d,f) should be attributed to the influence of DOW's plume. The temperature reduction between the upwelling area and the nonupwelling area was approximately $1.3^{\circ} \mathrm{C}$ at $22 \mathrm{~m}$ and $1.8^{\circ} \mathrm{C}$ at $18 \mathrm{~m}$, which indicates that the center of the plume is near $18 \mathrm{~m}$. Temperature sensors at 10 and $14 \mathrm{~m}$ recorded similar $T$ data, indicating a well-mixed situation at that vertical depths. The differences of the minimum $T$ at the 10- and 14-m layers between the two drifting trips are within $0.05^{\circ} \mathrm{C}$. The slow decline of temperatures at 18,14 , and $10 \mathrm{~m}$ during the trip in the nonupwelling area should be due to the relatively longer response time of temperature sensors (see T-18, T-14, and T-10, respectively, in Fig. 10). Although accurate thickness of the plume could not be recognized due to lack of data, it is rational to infer that the plume stays within the depth between 10 and $22 \mathrm{~m}$ where the temperature gradient exists as a result of mixing of DOW and the shallow water.

Simulations conducted on the prototype of the upwelling pipe for the identical sea state indicated that the 

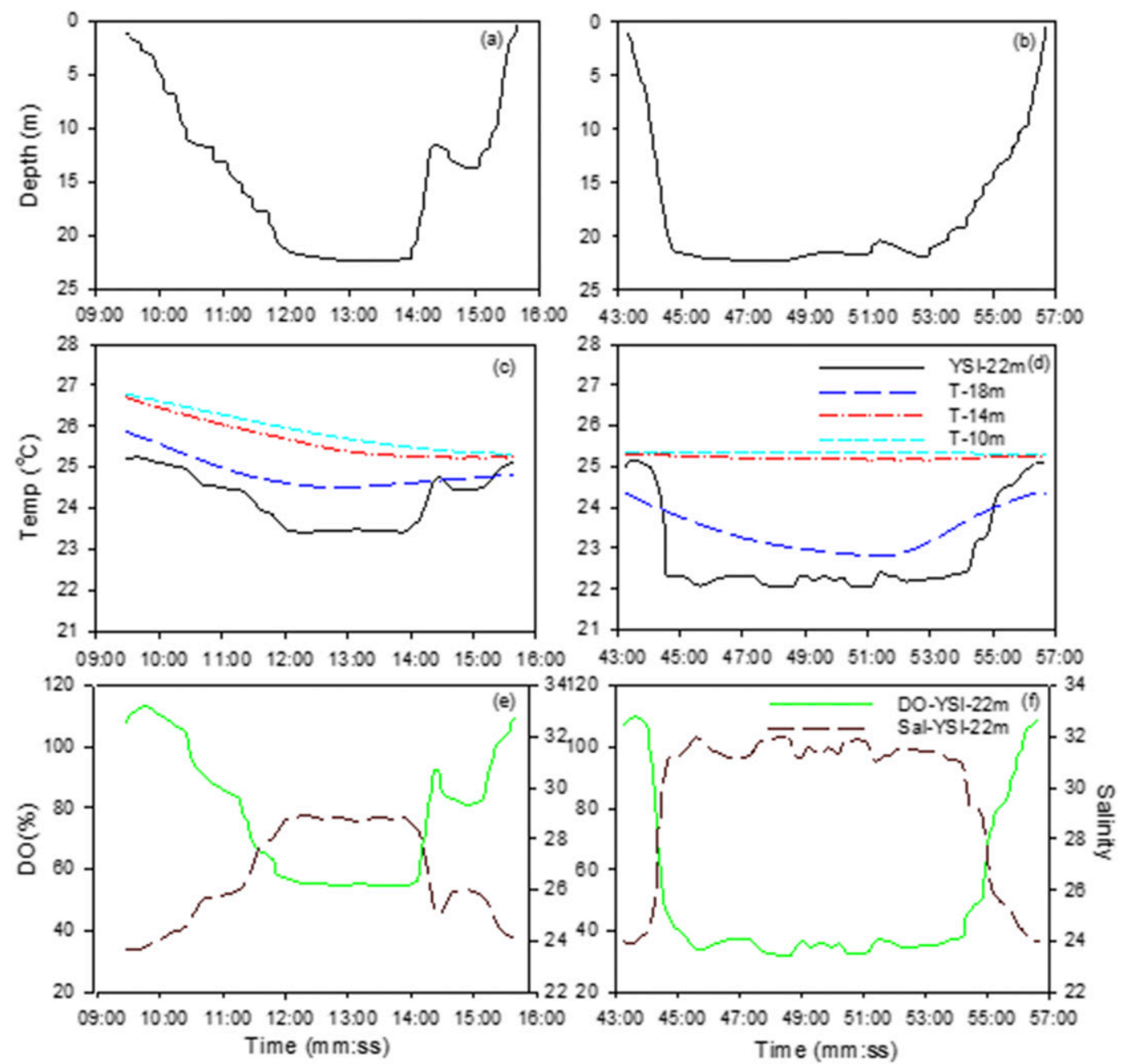

FIG. 10. Comparisons of depth, $T, S$, and DO data measured by the drifting buoy system between the (a),(c),(d) upwelling area and (b),(d),(f) nonupwelling area.

volume concentration of DOW in the plume can be controlled by setting up the flow rate, pipe diameter, and corresponding optimal DOW discharge depth. In the sea trial, DOW plume could be trapped by the density interface, which is around $23-25 \mathrm{~m}$, and the highest DOW volume concentration could be achieved in DOW's plume, which should be in the range of approximately $40 \%-50 \%$ when discharged at the optimal depth (Fan et al. 2015). In the light of measurement results, temperatures of the near-central plume were $22.9^{\circ} \pm 0.1^{\circ} \mathrm{C}$ at $18 \mathrm{~m}$ and $22.2^{\circ} \pm 0.1^{\circ} \mathrm{C}$ at $22 \mathrm{~m}$. Temperature of the ambient water in the discharging layer and the DOW (at $40 \mathrm{~m}$ ) are $24.65^{\circ}$ and $20.30^{\circ} \mathrm{C}$, respectively, which indicated that the plume at the depth of $18-22 \mathrm{~m}$ is composed of approximately $37 \%-51 \%$ DOW from $40 \mathrm{~m}$ mixed with ambient water during the turbulent entrainment. A conclusion can be drawn that the plume formed in the thermocline layer is a mixture of DOW and shallow water, and the mixing ratio conforms to the simulation result. The extremely large fraction of DOW concentration in the plume is mainly caused by the sharp vertical density profile in the sea trial area, which exhibits a strong thermocline and halocline region under the influences of CDW and TWWC.

\section{e. Estimated nutrient delivery and phytoplankton structure distribution}

The influences of CDW and TWWC make the sea area a strong thermocline and halocline region. Although the phosphate concentration exhibits a relatively low value in the upper layer compared to in the deeper layer, the $\mathrm{PO}_{4}^{3-}$ of the upper layer before the AU sea trial is approximately $0.5 \mu \mathrm{mol} \mathrm{L}{ }^{-1}$, which could be sufficient to support the growth of phytoplankton. The richer $\mathrm{N}$ and $\mathrm{Si}$ concentration in the upper thin layer make the region a nonideal place to test the biogeochemistry effects 

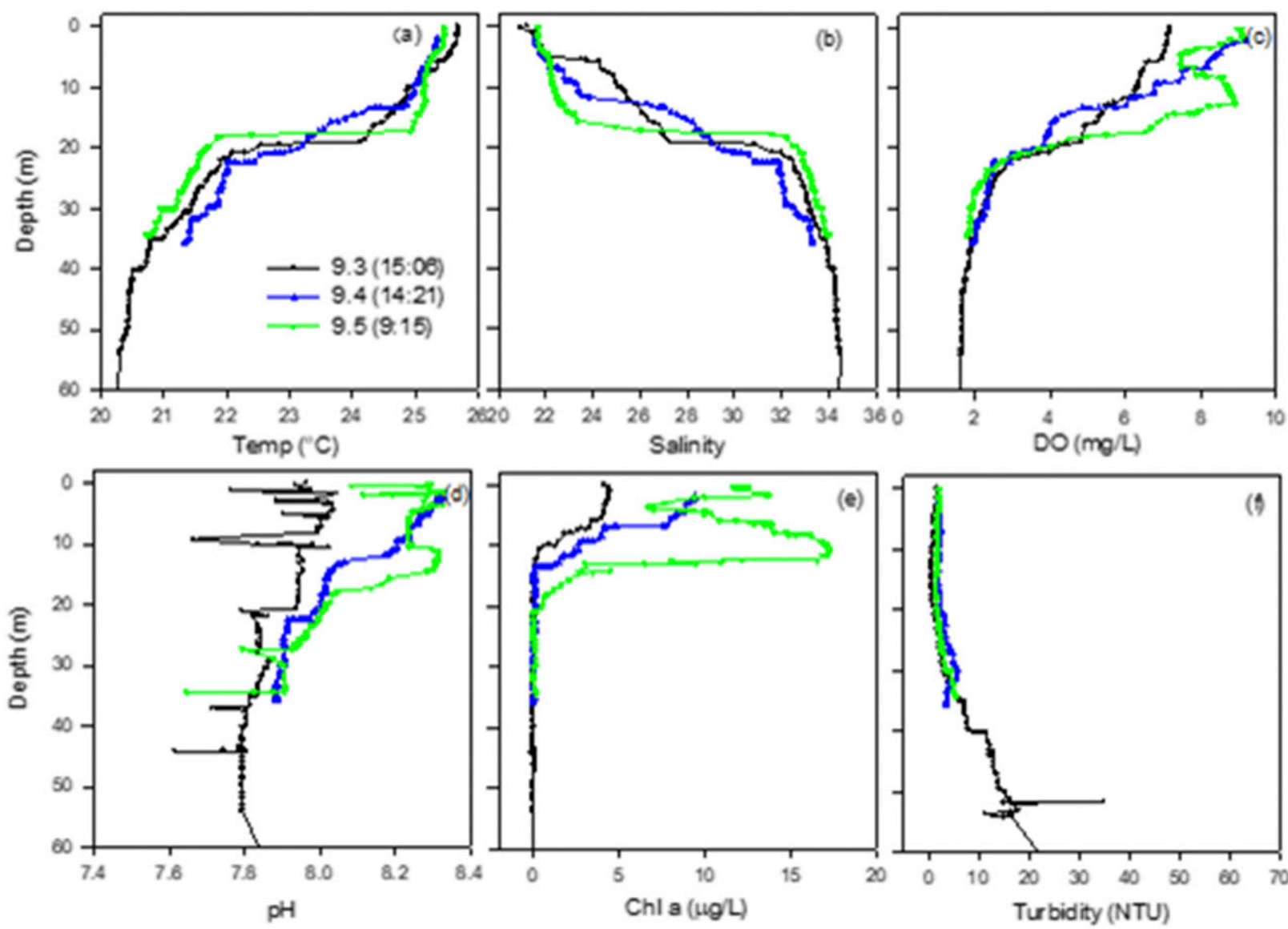

FIG. 11. Vertical distribution of (a) $T$, (b) $S$, (c) $\mathrm{DO}$, (d) $\mathrm{pH}$, (e) $\mathrm{Chl}$ a, and (f) turbidity near the pipe before the AU's application (3 Sep), during AU's application (4 Sep), and under the mixing effects of AU's application and beginning of diatom bloom (5 Sep).

of DOW uplifting. In fact, high fluorescence reaching $10 \mathrm{mg} \mathrm{m}^{-3}$ was detected with Prorocentrum minimum as the dominant phytoplankton species before the application of AU. P. minimum is described as an eurythermal and euryhaline species that can bloom under a wide range of environmental conditions (Fan et al. 2003; Fu et al. 2008). Although S. costatum, Ceratium furca, and Ceratium fusus were also observed, the proportion of $S$. costatum before AU was less than $1 \%$. According to the averaged measured upwelling rate of $0.055 \mathrm{~m} \mathrm{~s}^{-1}$ using a $1-\mathrm{m}$ diameter pipe, the flux that delivered from bottom layer to the upper layer is about $155.43 \mathrm{~m}^{3} \mathrm{~h}^{-1}$. Over the course of this experiment, the daily flux of uplifted DOW is about $1865 \mathrm{~m}^{3}$ day $^{-1}$ (The pump stopped at night). Given the measured nutrient concentrations of the source waters $(\sim 30 \mathrm{~m})\left(18.12 \mu \mathrm{mol} \mathrm{L}^{-1} \mathrm{NO}_{3}^{-}, 0.98 \mu \mathrm{mol} \mathrm{L}^{-1} \mathrm{PO}_{4}^{3-}\right.$, and $28.38 \mu \mathrm{mol} \mathrm{L}^{-1} \mathrm{SiO}_{4}^{3-}$ ), it could be estimated that the potential nutrient enrichments by uplifting that may have occurred during this trial are approximately $2.8 \mathrm{molh}^{-1}$ $\mathrm{NO}_{3}^{-}, 0.15 \mathrm{~mol} \mathrm{~h}^{-1} \mathrm{PO}_{4}^{3-}$, and $4.41 \mathrm{~mol} \mathrm{~h}^{-1} \mathrm{SiO}_{4}^{3-}$. Unfortunately, an $S$. costatum bloom occurred somewhere in the outer ECS and floated to the sea trial region at the second day of AU application. Intrusion of high-density S. costatum with relatively cold and saline water was monitored, which indicates the intrusion water mass from the outer ECS. Thus, it is hard to strip off the biochemical effects caused by AU from the effects of the $S$. costatum bloom, although differences in vertical distribution of phytoplankton biomass between the AU applied region and the other region could be observed (paper in preparation).

Alongside AU's application, the disturbance in the vertical hydrological structure could be observed as a relatively weaker stratification (Fig. 11). The stratification progressively became weaker after the beginning of AU's application, if the $T$ and $S$ profiles on 3 and 4 September at a similar time of day were compared. The stratification phenomena, however, became much stronger at 0915 LT 5 September after the AU stops work for one night. The apparent signal of the $S$. costatum bloom, yellow-green-colored seawater, occurred on the morning of 5 September, which corresponds to 
the measurements of enhanced $\mathrm{DO}, \mathrm{Chl}$ a, and $\mathrm{pH}$ signals in the upper layer (Figs. 11c-e). The bottom water DO, $\mathrm{Chl} \mathrm{a}$, and $\mathrm{pH}$ maintained relatively stable low values of approximately $1.8 \mathrm{mg} \mathrm{L}^{-1},<1 \mu \mathrm{g} \mathrm{L}^{-1}$, and 7.87 , respectively, below $30 \mathrm{~m}$. Off the Changjiang estuary, diatoms are the dominant phytoplankton community component especially in the summer season (Furuya et al. 2003). The turbidity after the beginning of AU's application did not increase immediately. A significant enhancement of turbidity below the thermocline layer could be observed on 6 and 7 September. Thus, the phenomena of $\mathrm{DO}$ production and $\mathrm{pH}$ increase were induced by primary production. The primary production enhancement and vertical structure should be influenced by both AU and intrusion of the high density of $S$. costatum. Although it is hard to strip off the biochemical effects by AU from the effects of the $S$. costatum bloom, it appears the application of AU increases the existing depths of the $S$. costatum bloom from near the surface to approximately $15 \mathrm{~m}$. The underlying mechanism is not clear yet. Further investigation is required.

\section{Conclusions}

The lack of prototype operating experience on openocean trials is a barrier to the implementation of artificial upwelling. In the present study, a sea trial of an air-lift concept AU system driven by self-powered energy was carried out in the East China Sea (ECS; $\left.30^{\circ} 8^{\prime} 14^{\prime \prime} \mathrm{N}, 122^{\circ} 44^{\prime} 59^{\prime \prime} \mathrm{E}\right)$ from 3 to 7 September 2014. The main purpose of the open-ocean trial is to assess the logistics of at-sea deployment and the durability of the equipment under extremely complex hydrodynamic conditions.

During the AU's application, cold, saline, low-DO, and low-pH DOW below the thermocline layer were measured to be uplifted from $30 \mathrm{~m}$ to the euphotic layer with a volumetric upwelling rate of $155.43 \mathrm{~m}^{3} \mathrm{~h}^{-1}$ and total inputs of $2.8 \mathrm{~mol} \mathrm{~h}^{-1} \mathrm{NO}_{3}^{-}, 0.15 \mathrm{~mol} \mathrm{~h}^{-1} \mathrm{PO}_{4}^{3-}$, and $4.41 \mathrm{~mol} \mathrm{~h}^{-1} \mathrm{SiO}_{4}^{3-}$, although in the sea trial station, the nitrate and silicate concentration above thermocline layer are richer than below the thermocline layer. A DOW's plume formed and was tracked by a drifting buoy system, with a mixing ratio of $37 \%-51 \%$ DOW at the depth of 18-22 m, which conforms to the simulation results. During the AU's application, although it is hard to strip off the biochemical effects by AU from the effects of the $S$. costatum bloom due to the mixing effect caused by diatom bloom somewhere in the outer ECS, the disturbance in the vertical hydrological structure could be observed. Besides, it seems like that the application of $\mathrm{AU}$ increases the existing depths of the
$S$. costatum bloom from near the surface to approximately $15 \mathrm{~m}$. Further analysis is required to investigate the underlying mechanism.

There are still a number of questions regarding artificial upwelling that need to be answered by the open-ocean trials: How can we develop a highly efficient and durable artificial upwelling devices that can survive in terrible sea conditions? What flow rate would be needed to enhance the oceanic primary productivity? Does artificial upwelling have the potential to succeed as a geoengineering technique to sequester anthropogenic $\mathrm{CO}_{2}$ in the open sea? These are major scientific and technical issues facing us. Today, artificial upwelling has received increasing attention worldwide due to its potential positive environmental effects. Therefore, we believe that the answers can be found in the future through increased open-ocean trials.

Acknowledgments. This research work is funded by the National Natural Science Funds of China (Grants 41776084 and 41976199), the National Key Research and Development Program of China (Grant 2016YFA0601400), and the Fundamental Research Funds for the Central Universities.

\section{REFERENCES}

Arrigo, K. R., D. H. Robinson, D. L. Worthen, R. B. Dunbar, G. R. Ditullio, M. V. Woert, and M. P. Lizotte, 1999: Phytoplankton community structure and the drawdown of nutrients and $\mathrm{CO}_{2}$ in the Southern Ocean. Science, 283, 365-367, https://doi.org/ 10.1126/science.283.5400.365.

Aure, J., O. Strand, S. R. Erga, and T. Strohmeier, 2007: Primary production enhancement by artificial upwelling in a western Norwegian fjord. Mar. Ecol. Prog. Ser., 352, 39-52, https:// doi.org/10.3354/meps07139.

Chen, C. T. A., 2008: Distributions of nutrients in the East China Sea and the South China Sea connection. J. Oceanogr., 64, 737-751, https://doi.org/10.1007/s10872-008-0062-9.

- 2009: Chemical and physical fronts in the Bohai, Yellow and East China seas. J. Mar. Syst., 78, 394-410, https://doi.org/ 10.1016/j.jmarsys.2008.11.016.

_ on the East China Sea continental shelf. J. Geophys. Res., 104, 20 675-20 686, https://doi.org/10.1029/1999JC900055.

Chen, J. W., Y. Chen, J. Yang, N. K. Liang, S. Lin, H. Ge, W. Fan, and H. C. Huang, 2013: Development of air-lifted artificial upwelling powered by wave. 2013 Oceans, San Diego, CA, IEEE, https://doi.org/10.23919/OCEANS.2013.6741101.

Dutkiewicz, S., M. J. Follows, and P. Parekh, 2005: Interactions of the iron and phosphorus cycles: A three-dimensional model study. Global Biogeochem. Cycles, 19, GB1021, https:// doi.org/10.1029/2004GB002342.

Fan, C. L., P. M. Glibert, and J. M. Burkholder, 2003: Characterization of the affinity for nitrogen, uptake kinetics, and environmental relationships for Prorocentrum minimum in natural blooms and laboratory cultures. Harmful Algae, 2, 283-299, https://doi.org/10.1016/S1568-9883(03)00047-7.

Fan, W., J. W. Chen, Y. W. Pan, H. C. Huang, C. T. A. Chen, and Y. Chen, 2013: Experimental study on the performance of an 
air-lift pump for artificial upwelling. Ocean Eng., 59, 47-57, https://doi.org/10.1016/j.oceaneng.2012.11.014.

—, Y. W. Pan, C. C. K. Liu, J. C. Wiltshire, C. T. A. Chen, and Y. Chen, 2015: Hydrodynamic design of deep ocean water discharge for the creation of a nutrient-rich plume in the South China Sea. Ocean Eng., 108, 356-368, https://doi.org/10.1016/ j.oceaneng.2015.08.006.

Fang, G. H., Y. G. Wang, Z. X. Wei, B. H. Choi, X. Y. Wang, and J. Wang, 2004: Empirical cotidal charts of the Bohai, Yellow, and East China Seas from 10 years of TOPEX/Poseidon altimetry. J. Geophys. Res., 109, C11006, https://doi.org/10.1029/ 2004JC002484.

Fu, F. X., Y. H. Zhang, M. E. Warner, Y. Y. Feng, J. Sun, and D. A. Hutchins, 2008: A comparison of future increased $\mathrm{CO}_{2}$ and temperature effects on sympatric Heterosigma akashiwo and Prorocentrum minimum. Harmful Algae, 7, 76-90, https:// doi.org/10.1016/j.hal.2007.05.006.

Furuya, K., M. Hayashi, Y. Yabushita, and A. Ishikawa, 2003: Phytoplankton dynamics in the East China Sea in spring and summer as revealed by HPLC-derived pigment signatures. Deep-Sea Res. II, 50, 367-387, http://doi.org/10.1016/S0967. 0645(02)00460-5.

Gong, G. C., J. Chang, K. P. Chiang, T. M. Hsiung, C. C. Hung, S. W. Duan, and L. A. Codispoti, 2006: Reduction of primary production and changing of nutrient ratio in the East China Sea: Effect of the Three Gorges Dam? Geophys. Res. Lett., 33, L07610, https://doi.org/10.1029/2006GL025800.

Guo, L., Y. Chen, F. J. Wang, X. Meng, Z. F. Xu, and G. S. Zhuang, 2014: Effects of Asian dust on the atmospheric input of trace elements to the East China Sea. Mar. Chem., 163, 19-27, https://doi.org/10.1016/j.marchem.2014.04.003.

Handå, A., T. A. McClimans, K. I. Reitan, Ø. Knutsen, K. Tangen, and Y. Olsen, 2013: Artificial upwelling to stimulate growth of non-toxic algae in a habitat for mussel farming. Aquacult. Res., 45, 1798-1809, https://doi.org/10.1111/are.12127.

Haskell, W. Z., D. Kadko, D. E. Hammond, A. N. Knapp, M. G. Prokopenko, W. M. Berelson, and D. G. Capone, 2015: Upwelling velocity and eddy diffusivity from ${ }^{7} \mathrm{Be}$ measurements used to compare vertical nutrient flux to export POC flux in the eastern tropical South Pacific. Mar. Chem., 168, 140-150, https://doi.org/10.1016/j.marchem.2014.10.004.

Hung, C. C., and G. C. Gong, 2011: Biogeochemical responses in the southern East China Sea after typhoons. Oceanography, 24 (4), 42-51, https://doi.org/10.5670/oceanog.2011.93.

Kadko, D., and W. Johns, 2011: Inferring upwelling rates in the equatorial Atlantic using ${ }^{7} \mathrm{Be}$ measurements in the upper ocean. DeepSea Res. I, 58, 647-657, https://doi.org/10.1016/j.dsr.2011.03.004.

Kirke, B., 2003: Enhancing fish stocks with wave-powered artificial upwelling. Ocean Coastal Manage., 46, 901-915, https:// doi.org/10.1016/S0964-5691(03)00067-X.

Liang, N. K., and H. K. Peng, 2005: A study of air-lift artificial upwelling. Ocean Eng., 32, 731-745, https://doi.org/10.1016/ j.oceaneng.2004.10.011.

Lovelock, J. E., and C. G. Rapley, 2007: Ocean pipes could help the Earth to cure itself. Nature, 449, 403-403, https://doi.org/ 10.1038/449403a.

Maruyama, S., T. Yabuki, T. Sato, K. Tsubaki, A. Komiya, M. Watanabe, H. Kawamura, and K. Tsukamoto, 2011 Evidences of increasing primary production in the ocean by Stommel's perpetual salt fountain. Deep-Sea Res. I, 58, 567-574, https://doi.org/10.1016/j.dsr.2011.02.012.

Masuda, T., K. Furuya, N. Kohashi, M. Sato, S. Takeda, M. Uchiyama, N. Horimoto, and T. Ishimaru, 2010: Lagrangian observation of phytoplankton dynamics at an artificially enriched subsurface water in Sagami Bay, Japan. J. Oceanogr., 66, 801-813, https://doi.org/10.1007/s10872-010-0065-1.

McClimans, T. A., G. Eidnes, and J. Aure, 2002: Controlled artificial upwelling in a fjord using a submerged fresh water discharge: Computer and laboratory simulations. Hydrobiologia, 484, 191-202, https://doi.org/10.1023/ A:1021369408346.

Mizumukai, K., T. Sato, S. Tabeta, and D. Kitazawa, 2008: Numerical studies on ecological effects of artificial mixing of surface and bottom waters in density stratification in semienclosed bay and open sea. Ecol. Modell., 214, 251-270, https://doi.org/10.1016/j.ecolmodel.2008.02.023.

Ouchi, K., K. Otsuka, and H. Omura, 2005: Recent advances of ocean nutrient enhancer "TAKUMI" project. Proc. Sixth Ocean Mining Symp., Changsha, China, International Society of Offshore and Polar Engineers, ISOPE-M-05-002.

Pan, Y. W., W. Fan, T. H. Huang, S. L. Wang, and C. T. Chen, 2015: Evaluation of the sinks and sources of atmospheric $\mathrm{CO}_{2}$ by artificial upwelling. Sci. Total Environ., 511, 692-702, https:// doi.org/10.1016/j.scitotenv.2014.11.060.

, and Coauthors, 2016: Research progress in artificial upwelling and its potential environmental effects. Sci. China Earth Sci., 59, 236-248, https://doi.org/10.1007/s11430-015-5195-2.

L. You, Y. F. Li, W. Fan, C. T. Chen, B. J. Wang, and Y. Chen, 2018: Achieving highly efficient atmospheric $\mathrm{CO}_{2}$ uptake by artificial upwelling. Sustainability, 10, 664, https:// doi.org/10.3390/su10030664.

Qiang, Y., W. Fan, C. Xiao, Y. Pan, J. P. Wu, and Y. Chen, 2018: Effects of operating parameters and injection method on the performance of an artificial upwelling by using airlift pump. Appl. Ocean Res., 78, 212-222, https://doi.org/10.1016/ j.apor.2018.06.006

Shen, Z. B., X. B. Wu, Y. J. Fei, X. A. Xu, and X. F. Chen, 2013: Surface tidal currents in the open sea area to the east of the Zhoushan Islands measured with high frequency surface wave radar. Acta Oceanol. Sin., 32, 5-10, https://doi.org/10.1007/ s13131-013-0359-4.

Su, J. L., 1998: Circulation dynamics of the China Seas: North of $18^{\circ} \mathrm{N}$. The Global Coastal Ocean: Regional Studies and Syntheses, A. R. Robinson and K. H. Brink, Eds., The SeaIdeas and Observations on Progress in the Study of the Seas, Vol. 11, John Wiley and Sons, 483-505.

Tsuchiya, K., V. S. Kuwahara, T. M. Yoshiki, R. Nakajima, S. Shimode, T. Kikuchi, and T. Toda, 2017: Response of phytoplankton and enhanced biogeochemical activity to an episodic typhoon event in the coastal waters of Japan. Estuarine Coastal Shelf Sci., 194, 30-39, https://doi.org/ 10.1016/j.ecss.2017.05.019.

Wang, W. T., Z. M. Yu, X. X. Song, Y. Q. Yuan, Z. X. Wu, P. Zhou, and X. H. Cao, 2018: Intrusion pattern of the offshore Kuroshio branch current and its effects on nutrient contributions in the East China Sea. J. Geophys. Res. Oceans, 123, 2116-2128, https://doi.org/10.1002/2017JC013538.

White, A., K. Björkman, E. Grabowski, R. Letelier, S. Poulos, B. Watkins, and D. Karl, 2010: An open ocean trial of controlled upwelling using wave pump technology. J. Atmos. Oceanic Technol., 27, 385-396, https://doi.org/10.1175/ 2009JTECHO679.1.

Williamson, N., A. Komiya, S. Maruyama, M. Behnia, and S. W. Armfield, 2009: Nutrient transport from an artificial upwelling of deep sea water. J. Oceanogr., 65, 349-359, https://doi.org/ 10.1007/s10872-009-0032-x. 
Yang, D. Z., B. S. Yin, Z. L. Liu, T. Bai, J. F. Qi, and H. Y. Chen, 2012: Numerical study on the pattern and origins of Kuroshio branches in the bottom water of southern East China Sea in summer. J. Geophys. Res., 117, C02014, https://doi.org/ 10.1029/2011JC007528.

Ye, H. J., Y. Sui, D. L. Tang, and Y. D. Afanasyev, 2013: A subsurface chlorophyll a bloom induced by typhoon in the South China Sea. J. Mar. Syst., 128, 138-145, https://doi.org/10.1016/ j.jmarsys.2013.04.010.

Zhang, D. H., G. Aggidis, Y. F. Wang, A. McCabe, and W. Li, 2013: Experimental results from wave tank trials of a multi-axis wave energy converter. Appl. Phys. Lett., 103, 103901, https:// doi.org/10.1063/1.4820435.

, W. Fan, J. Yang, Y. W. Pan, Y. Chen, H. C. Huang, and J. W. Chen, 2016: Reviews of power supply and environmental energy conversions for artificial upwelling. Renew. Sustain. Energy Rev., 56, 659-668, https://doi.org/10.1016/ j.rser.2015.11.041.
Zhang, F. Y., J. Sun, B. L. Lin, and G. X. Huang, 2018: Seasonal hydrodynamic interactions between tidal waves and river flows in the Yangtze estuary. J. Mar. Syst., 186, 17-28, https:// doi.org/10.1016/j.jmarsys.2018.05.005.

Zhang, X. R., S. Maruyama, S. Sakai, K. Tsubaki, and M. Behnia, 2004: Flow prediction in upwelling deep seawater-The perpetual salt fountain. Deep-Sea Res. I, 51, 1145-1157, https:// doi.org/10.1016/j.dsr.2004.03.010.

Zheng, J. H., Y. X. Yan, C. F. Tong, Z. Y. Lei, and C. Zhang, 2012: Hydrodynamic and morphological processes in Yangtze estuary: State-of-the-art research and its applications by Hohai University. Water Sci. Eng., 5, 383-398, https://doi.org/10.3882/ j.issn.1674-2370.2012.04.003.

Zhu, L., Y. Chen, L. Guo, and F. J. Wang, 2013: Estimate of dry deposition fluxes of nutrients over the East China Sea: The implication of aerosol ammonium to non-sea-salt sulfate ratio to nutrient deposition of coastal oceans. Atmos. Environ., 69 , 131-138, https://doi.org/10.1016/j.atmosenv.2012.12.028. 